\title{
Territorialidade religiosa: uma análise da Igreja Profética Batista da Restauração na região metropolitana de Belém-PA
}

\section{The role of the religious discourse on the ethnocultural identity construction from the Italian immigrants in Curitiba at the end of the 19th century}

\author{
Paulo Afonso Dias de Lima* \\ Mirleide Chaar Bahia** \\ Léa Maria Gomes da Costa***
}

Resumo: A presente pesquisa tem como objeto de estudo uma Igreja de rito pentecostal, a Igreja Profética Batista da Restauração (IPBR), localizada na Região Metropolitana de Belém. O objetivo da pesquisa consiste em compreender a principal prática territorial utilizada pela instituiçâo religiosa no tocante ao controle e aquisiçáo de novos territórios para ampliação de sua territorialidade religiosa. Para viabilizar o alcance do objetivo supracitado, foram realizadas pesquisas de campo no local estudado e entrevistas semiestruturadas com pastores e demais membros da Igreja.

Palavras-chave: Território. Territorialidade. Redes. Geografia da religiáo. Pentecostalismo.

Abstract: The present research focuses on the study of a Pentecostal rite church, the Igreja Profética Batista da Restauraçáo, located in the Metropolitan Region of Belém as the object of study. The objective of the research is to understand the primary territorial practice used by the religious institution in the control and acquisition of new territories for the expansion of its religious territoriality. In order to achieve this objective, fieldwork was carried out at the study site, and semi-structured interviews were conducted with pastors and other members of the Church.

Keywords: Territory. Territoriality. Networks. Geography of religion. Pentecostalism.

\section{Introduçáo}

Constatou-se, a partir da análise dos censos demográficos do Instituto Brasileiro de Geografia e Estatística (IBGE), que, no cenário brasileiro dos últimos anos, houve um rápido crescimento do pentecostalismo. No período de 1980 a 2010, o Instituto, através de pesquisas, avaliou que o percentual de protestantes evangélicos passou de

\footnotetext{
* Mestrando em Desenvolvimento Sustentável do Trópico Úmido (UFPA). Bolsista CNPq. ORCID: 0000-0001-9592-9346 - contato: pauloafonso800@gmail.com

** Doutora em Desenvolvimento Socioambiental (UFPA). Professora do PPG em Desenvolvimento Sustentável do Trópico Úmido (UFPA). ORCID: 0000-0001-7168-2019 - contato: mirleidebahia@gmail.com

*** Doutoranda em Geografia (UFPA). Professora de Geografia na UEPA. ORCID: 0000-0002-13270531 - contato: $\underline{\operatorname{lmgc1298@yahoo.com} . b r}$
} 
$6,6 \%$ para $22,2 \%$, sendo o maior crescimento observado no segmento religioso analisado (IBGE, 2010).

No período mais recente, de 2000 a 2010, a partir do número total de pessoas, avaliou-se que o segmento deu um salto de 16 milhóes de pessoas, ou seja, em apenas dez anos passou de 26,2 milhões para 42,3 milhões de seguidores. Esses dados demonstram a importância do movimento religioso que mais cresce no Brasil (IBGE, 2010).

Considerando novamente o percentual sobre a população evangélica, segundo a análise do Instituto Brasileiro de Geografia e Estatística, verifica-se, além do crescimento no número total da população evangélica, que o movimento pentecostal é o que mais cresce dentro dos que se declaram evangélicos: "[...] o crescimento da população evangélica, que passou 15,4\% em 2000 para 22,2\% em 2010. Dentro do mesmo grupo, declarantes evangélicos, 60,0\% eram de origem pentecostal, 18,5\% evangélicos de missão e 21,8\% evangélicos não determinados" (IBGE, 2010, s.p).

Quando se analisa a capital do estado do Pará, Belém, no que se refere ao crescimento dos diversos movimentos religiosos, acredita-se necessária a produção de pesquisas que versem sobre a relação geografia e religião, considerando que Belém é uma metrópole sob a influência constante de movimentos religiosos já consolidados, a exemplo da Igreja Católica, que promove uma das maiores festas religiosas do mundo, o Círio de Nazaré, além da primeira Igreja pentecostal do Brasil, a já centenária Assembleia de Deus. Diante desse quadro, considera-se que o fenômeno religioso e seus aspectos geográficos necessitam ser estudados amplamente na capital paraense.

A geografia da religião, que dá norte à pesquisa, busca analisar a espacialidade do sagrado e sua dimensão simbólica. Os estudos geográficos da religião basearam-se, principalmente, na pesquisa da geógrafa Zeny Rosendahl (2003). Desta forma, no presente artigo, daremos ênfase à dimensão política em especial, posto que esta destaca os estudos que associam temas como Religião, Território e Territorialidade. Para este artigo, foi abordado o território religioso de uma instituiçáo religiosa - a Igreja Profética Batista da Restauração (IPBR) -, que, ligada ao movimento pentecostal, exerce, a partir de leis e diretrizes de difusão e manutenção da fé, a sua territorialidade (Rosendahl, 2003).

Diante disso, o objetivo da pesquisa consiste em compreender a principal prática territorial utilizada pela IPBR na manutenção e aquisição de novos territórios. Sendo essencial para o alcance dos objetivos propostos a compreensão da principal prática para a manutenção e expansão de seu território; as características desta prática e o alcance territorial alcançado pela IPBR atráves desta dinâmica.

\section{Metodologia}

A metodologia desta pesquisa baseou-se em uma abordagem qualitativa e observações no campo, de caráter participativo (Creswell, 2007). Como estratégia de pesquisa, optou-se pela utilização de um estudo de caso (Yin, 2005; Lajeado, 2011), além de dois tipos de entrevistas com perguntas semi-estruturadas (Gaskell, 2009), a primeira realizada junto aos pastores da Igreja e a segunda aos demais membros da IPBR, tendo como objetivo elucidar suas características e estrutura de funcionamento. 
Um estudo de caso possui a função de transmitir observações sobre um fenômeno passado ou atual, e pode ser elaborado com o auxílio de um referencial teórico que guia as questóes do estudo, de dados de observação em campo e a utilização de entrevistas (Freitas; Jabbour, 2011). Para Yin (2005, p. 32), "o estudo de caso é uma investigação empírica que investiga um fenômeno contemporâneo dentro de seu contexto da vida real"; deste modo, sendo complementar à observação participante utilizada no estudo, sendo a mesma "realizada em contacto direto, frequente e prolongado do investigador, com os atores sociais, nos seus contextos culturais, sendo o próprio investigador instrumento de pesquisa" (Correia, 1999, p. 31).

Considerando que a pesquisa versará sobre os temas de Religiáo e Sociedade, acredita-se que os "métodos de presença" continuarão a ser centrais para o "projeto antropológico de compreender o mundo" e, por extensão, para o trabalho de campo sobre as religiôes (Hastrup; Hervik, 1994, p. 3).

A opção metodológica de "participar" visa colocar o pesquisador de forma menos "invasiva" no cotidiano dos participantes, diminuindo o risco de os mesmos demonstrarem artificialidades ao discorrer sobre suas experiências. Tomando como exemplo os estudos sobre religióes, é importante que a participação ativa não "embriague" a pesquisa, para que o pesquisador não assuma nem uma postura puramente cética, nem transforme os dogmas e crenças religiosas em verdades universais.

A observação participante ao focar, essencialmente, na atribuição de significados para as vivências, torna-se relevante na medida em que o universo religioso é carregado de símbolos e significados que, em sua maioria, não são compreendidos por pessoas de fora desse universo (Geertz, 1989). O resultado esperado com a pesquisa participante será de descobrir e tornar acessíveis (no sentido de revelar) realidades e significados religiosos que as pessoas utilizam para nortear ou atribuir sentido às suas vidas (Monico et al, 2017).

A análise dos resultados alcançados com a pesquisa foi feita relacionando o suporte empírico, obtido por meio das observaçóes e da aplicação dos instrumentos de coleta de dados, com os conceitos utilizados pelos autores que embasaram o suporte teórico.

Os questionários foram elaborados de modo a dispensar a identificação nominal do indivíduo. Três perguntas do Questionário 1 (pastores) referem-se ao surgimento da Igreja e como a mesma se enquadra nos movimentos desencadeados pelo protestantismo. Outras cinco perguntas referem-se a informaçóes sobre como a IPBR está organizada internamente e sobre o funcionamento da dinâmica de células. A percepção individual de cada pastor entrevistado foi instigada com perguntas complementares, gerando respostas diversificadas.

No segundo questionário (demais membros da Igreja), duas perguntas foram sobre os motivos que os levaram a participar da IPBR. Três perguntas referem-se à percepção e participação na estrutura e organização da Igreja. Já as últimas duas perguntas referem-se à dinâmica de células, esclarecendo seus benefícios e dificuldades.

O grupo participante da pesquisa foi composto por 9 pastores e 26 membros, dos quais eram 6 adolescentes de 11 a 17 anos, 9 jovens de 18 a 30 anos, 15 adultos de 31 a 50 anos e 5 adultos acima de 50 anos de idade, totalizando 35 pessoas.

É importante salientar que foi concedida total tolerância dos pastores da Igreja e que o apoio dos líderes religiosos resultou em uma maior interação entre entrevistados e entrevistador. 
$\mathrm{O}$ recorte temporal deste trabalho foram os anos de 2016 e 2017 . Acentua-se que esse recorte remonta ao período em que foi feita a pesquisa, a qual está relacionada a monografia de conclusão de curso do autor. Análises mais recentes sobre o mesmo assunto e o objeto náo estáo incluídas neste texto, pois preferiu-se trazer o resultado final de pesquisa obtido naquele momento e náo a retomada com uma nova pesquisa que comtemplasse o presente.

\section{Território e territorialidade}

Inúmeras são as conceituações, conotações e abordagens do conceito de território na Geografia. Porém, o conceito de território aqui tratado privilegia um duplo aspecto, que considera tanto uma conotação material quanto uma simbólica. Para tal, sobre este, utiliza-se o pensamento de Haesbaert (2007), reconhecendo essa dupla conotação do conceito:

Desde a origem, o território nasce com uma dupla conotação, material e simbólica, pois etimologicamente aparece táo próximo de terra-territorium quanto de térreo-territor (terror, aterrorizar), ou seja, tem a ver com dominação (jurídico-política) da terra e com a inspiraçáo do terror, do medo - especialmente para aqueles que, com esta dominaçáo, ficam alijados da terra, ou no "territorium" são impedidos de entrar. Ao mesmo tempo, por outro lado, podemos dizer que, para aqueles que têm o privilégio de plenamente usufrui-lo, o território pode inspirar a identificaçáo (positiva) e a efetiva "apropriação" (Haesbaert, 2007, p. 20).

É necessário esclarecer que território, considerado em qualquer uma de suas abordagens, tem relaçóes com o poder e que este não se restringe ao Estado e não se deve confundir com violência e dominação (Haesbaert, 2004). Dessa forma, o território pode ser entendido como uma área específica controlada e gerida por uma pessoa ou por um grupo de pessoas, criado, como citado acima, por e a partir de relações de poder (Souza, 2000).

O território é sempre múltiplo, complexo e diverso, além de estar imerso em relaçôes de dominação e apropriação entre a sociedade e o espaço. Uma multiplicidade de poder é exercido e manifestado através de uma multiplicidade de agentes, tanto hegemônicos quanto contra-hegemônicos. Dessa maneira, no território, manifestam-se as lutas de resistências, visto que, na visão de Haesbaert (2004), poder sem resistência não existe.

A partir dessa afirmação, faz-se necessário afirmar que, em conformidade com o pensamento de Souza (2013), se alguém controla e mantém o poder no espaço, influências serão exercidas formal ou informalmente por algum tipo de governo, lembrando, mais uma vez, que não será um governo estatal institucionalizado. É relevante refletir quem é dominado e quem é dominante, quem influencia e quem é influenciado, quem governa e quem é governado, e por que o faz, vinculando também aqui as diversas relaçóes, não só políticas, mas afetivas e de identidade entre um grupo e seu espaço.

À luz do que foi dito nos parágrafos anteriores, já deve estar claro que governo, do meu ponto de vista, não é sinônimo de governo estatal, e que mesmo em uma sociedade não heterônoma existirá algum tipo de governo (autogoverno), e influências serão exercidas, em contextos informais e também formalmente deliberativos, por alguns indivíduos sobre outros. [...] por que razóes se deseja territorializar um espaço e manter 
o controle sobre ele? Há, potencialmente, uma plêiade de motivaçóes. O que se pode dizer, conforme eu já havia grifado em 1995, é que essas motivaçōes sempre estarão, de algum modo, conectadas ao substrato espacial material e, eventualmente, também aos próprios significados culturais atribuídos as formas espaciais, isto é, às imagens do lugar. O desejo ou a cobiça com relação a um espaço podem ter relação com os recursos naturais da área em questáo; podem ter a ver com o que se produz ou quem produz no espaço considerado; podem ter ligação com o valor estratégico-militar daquele espaço especifico; e podem se vincular, também, às ligaçóes afetivas e de identidade entre um grupo social e seu espaço (ou, mais especificamente, entre um grupo e objetos geográficos determinados, como um santuário ou símbolo "nacional”) (Souza, 2013, p. 86-88).

Analisando o conceito dado pelo autor e entendendo a necessidade de compreender os sujeitos que controlam e detêm o poder no território, é necessário admitir que existem práticas de cada grupo ou de cada pessoa que possui e controla um território; maneiras, ou melhor, estratégias, para gerir, manter e formar os territórios - a isto chamamos de territorialidades (Sack, 1986).

Territorialidade possui uma dimensão imaterial necessária para a existência do território. Essa dimensão pode se inserir, enquanto estratégia política de caráter físico, no controle de determinado espaço, como imaterialidade também em um controle, porém um controle simbólico - através da construção de identidades e como "espaço vivido", reagindo a territórios formais e institucionalizados (Haesbaert, 2007). Através dessa revisão teórica elaborada pelo autor sobre as diversas formas com que a concepção de territorialidade foi proposta, podemos sintetizar o seguinte elenco de posições:
1) Territorialidade num enfoque mais epistemológico:
"abstração", condição genérica (teórica) para a existência do território, dependendo, assim, do conceito de território proposto).
2) Territorialidade num sentido mais ontológico:
a. Como materialidade (ex. controle físico do acesso através do espaço material, como indica Robert Sack).
b. Como imaterialidade (ex. controle simbólico, através de uma identidade territorial ou "comunidade territorial imaginada").
c. Como "espaço vivido" (frente aos espaços - neste caso, territórios, formais-institu- cionais), conjugando materialidade e imaterialidade (Haesbaert, 2007, p. 7).

Territorialidade é essencial, também, para se entender a relação espaço-tempo e como o território foi construído historicamente por um determinado grupo social. Para Sack (1986):
A Territorialidade é uma expressão geográfica primária do poder social. Ela é um meio pelo qual o espaço e o tempo estão inter-relacionados. A mudança de funçóes da Territorialidade nos ajuda a entender as relaçóes históricas entre a sociedade, o espaço e o tempo (Sack, 1986, p. 22).

A territorialidade é uma estratégia para reavivar, constantemente, o poder e a influência sobre um espaço, usando-se da dominaçáo. A territorialidade pode mascarar seus verdadeiros objetivos de controle, sempre deixando marcas, uma linguagem no espaço, que será entendida por quem ou o que se quer controlar e influenciar, de forma simbólica ou visível.

Segundo, por definição, a Territorialidade deve conter uma forma de comunicação. Isto pode envolver uma marca ou sinal, tal como é comumente encontrada em uma 
fronteira. Ou uma pessoa pode criar uma fronteira, através de um gesto, tal como apontar uma fronteira territorial, pode ser somente a forma simbólica que combina uma afirmação sobre a direção no espaço e uma afirmação sobre a posse ou exclusão (Sack, 1986, p. 24).

De acordo com o que vem sendo abordado, a territorialidade náo é uma relaçáo neutra. Ela envolve poder, pessoas em relaçôes de energia e informação. Neste sentido:

\begin{abstract}
A Territorialidade, então, forma um cenário para as relações espaciais humanas e as concepçóes do espaço. A Territorialidade aponta para o fato de que as relaçóes espaciais humanas não são neutras. As pessoas, simplesmente, não interagem no espaço e se movem através do espaço como bolas de bilhar. Ao invés disso, a interação humana, o movimento e o contato são também questôes de transmissão de energia e informação, para afetar, influenciar e controlar as ideias e açóes de outros e seus acessos às fontes. As relaçóes espaciais humanas são resultados da influência e poder. A Territorialidade é a forma espacial primária do poder (Sack, 1986, p. 30).
\end{abstract}

Entendendo o conceito de território e territorialidade através dessa análise teórica, é preciso agora atribuir um adjetivo aos conceitos, para que eles melhor respondam ao que a pesquisa pretende e para que melhor se encaixem na análise aqui desenvolvida. Portanto, trataremos agora com os conceitos de território e territorialidade especificamente voltados para a análise religiosa, ou seja, território religioso e territorialidade religiosa.

\title{
Território e territorialidade religiosa
}

Destaca-se que o poder e o controle do território e das práticas para gerir e expandi-lo estão nas mãos de sujeitos, sejam estes um grupo ou apenas um indivíduo. Desse modo, o poder no sagrado e sobre os instrumentos deste estão nas mãos dos sujeitos que o controlam, como já assinalado; é o poder dos especialistas do sagrado, dos clérigos, bispos e pastores, que controlam o território religioso (Rosendahl, 2012).

O território é um importante instrumento de exercício da fé e da identidade religiosa. Do espaço sagrado emana um sentimento de identidade, de pertencimento e de propriedade; reconhece-se, então, que a crença no sagrado, a identidade e relaçáo de cada indivíduo com o espaço sagrado, participam na formação e na redefinição do território, como destaca Rosendahl (2012, p. 87):

Territórios religiosos são definidos como espaços qualitativamente fortes, compostos de fixos e fluxos, e possuidores de funçôes e formas espaciais que constituem os meios por intermédio dos quais o território realiza efetivamente os papeis a ele atribuídos pelo agente social que o criou e controla (Rosendahl, 2002; 2008). [...] Apresenta, além do caráter político, nítido caráter cultural, especialmente quando os agentes sociais são grupos étnicos-religiosos. Território e identidade religiosa estão fortemente ligados. O sagrado reflete tanto uma identidade de fé quanto um sentimento de propriedade mútuo (Rosendahl, 2012, p. 87).

Na perspectiva da autora, o território pode ser compreendido nas diversas dimensóes do sagrado, a saber: econômica, política e econômica. A presente pesquisa não desconsidera as dimensões econômicas e do lugar, porém tem como foco o aspecto político da relação entre o sagrado e o território. Sendo assim, é necessário compreender que todas as relaçôes sociais são relações de poder e que, no que se refere à multiplicidade 
de sujeitos e relações no espaço, para se compreender o território, é preciso entender quem efetivamente exerce o poder, seja de uma forma visível ou simbólica, além de reconhecer "quem domina quem" no território e quais estratégias usa para isto, como escreve Haesbaert (2007):

Território, assim, em qualquer acepçáo, tem a ver com poder, mas não apenas ao tradicional "poder político". Ele diz respeito tanto ao poder no sentido Território e Multiterritorialidade: Um debate mais explícito, de dominação, quanto ao poder no sentido mais implícito ou simbólico, de apropriação (Haesbaert, 2007, p. 20).

O território da IPBR pode ser compreendido tanto por meio de seu caráter político como também pelo cultural. O espaço se torna território na apropriação, no estabelecimento das fronteiras imaginárias. Quando os agentes sociais organizam e estruturam o território, o fazem para garantir o controle, vigiar, expandir sua influência, garantindo sua existência. Referindo-se às múltiplas consideraçōes dos geógrafos sobre o conceito território, Rosendahl (2012) sintetiza:

O território constitui-se em dado segmento do espaço, geralmente delimitado, que resulta da apropriação e do controle por parte de determinado agente social, um grupo humano, uma empresa ou uma instituição, como o Estado ou outra organização social. Além do caráter político, apresenta um nítido caráter cultural, especialmente quando os agentes sociais são grupos étnicos e religiosos (Rosendahl, 2012, p. 51).

É preciso ressaltar que são múltiplas as estratégias que interligam religião e território. A dimensão política do sagrado objetiva investigar as normas e formas adotadas pelas instituiçôes religiosas, a fim de assegurar a vivência da fé e a vigilância dos fiéis, afirmando, assim, sua identidade religiosa (Rosendahl, 2012). É necessário ter o conhecimento sobre os simbolismos do sagrado, que são produzidos, consumidos e geridos, como aponta Rosendahl (2005):

Essa questão envolve o conhecimento da religião como um sistema de símbolos sagrados e seus valores, envolvendo a produção, o consumo, o poder, as localizaçóes, os fluxos e os agentes sociais em suas dimensóes econômica, política e do lugar. Portanto, o território está presente em todas estas dimensóes (Rosendahl, 2005, p. 02).

De acordo com as ideias de Rosendahl (2005), para consolidar, apropriar e manter o controle sobre o território, essas instituiçóes se utilizam de práticas específicas, que denominamos de territorialidades. Essas estratégias para gerir, manter e formar os territórios na religião estão ligadas ao controle de pessoas e objetos e às experiências sobrenaturais em um determinado espaço, tornando-o um lugar sagrado e fortalecendo as territorialidades religiosas. Corroborando Rosendahl (2005) em relaçáo a um aspecto mais cultural das territorialidades, Haesbaert (2007) afirma:

A territorialidade, além de incorporar uma dimensão mais estritamente política, diz respeito também às relaçôes econômicas e culturais, pois está "intimamente ligada ao modo como as pessoas utilizam a terra, como elas próprias se organizam no espaço e como elas dão significado ao lugar" (Haesbaert, 2007, p. 22).

Assim como no território religioso, a territorialidade religiosa está carregada de caráter cultural, usada como forma de afirmação de identidades e de caráter dominante 
e influenciador sobre pessoas e objetos (Rosendahl, 2012). "A territorialidade é fortalecida pelas experiências religiosas coletivas ou individuais que o grupo mantém no lugar sagrado e nos itinerários que constituem seu território. De fato, é pelo território que se encarna a relação simbólica que existe entre cultura e espaço" (Rosendahl, 2005, p. 7).

Esta estratégia para gerir, manter e formar os territórios na religião está ligada ao controle de pessoas e objetos e às experiências sobrenaturais no determinado espaço, tornando um lugar sagrado e fortalecendo as territorialidades religiosas, e isto através de símbolos, simbologias e significados.

Considerando a Territorialidade pentecostal, leva-se em conta o estudo de Machado (1994), o qual considera essa territorialidade enquanto uma estratégia de apropriação espacial essencialmente dinâmica, transitória e efêmera, porém com a capacidade de se adequar aos mais diversificados espaços, o que a permite acompanhar o movimento da sociedade moderna.

\section{O alcance territorial da Igreja e as células}

A fundação da Igreja Profética Batista da Restauração (IPBR) ocorreu em 2009, portanto a mesma completou sete anos em 2017. O Local de sua implantação foi o bairro do Coqueiro, em Ananindeua, a segunda maior cidade da Região Metropolitana de Belém (IBGE, 2010).

A sede da IPBR localiza-se no bairro do Coqueiro, em Ananindeua, segunda maior cidade da Regiáo Metropolitana de Belém (RMB). Fundada em 2009, a Igreja mantém, no momento da pesquisa, uma filial na capital do Estado, Belém, situada no bairro da Cabanagem $^{1}$, área de expansão urbana, assim como diversas células dispostas na RMB.

A IPBR conta, atualmente, com aproximadamente 400 membros, um templo filial e 12 células na RMB. A pastora presidente da IPBR associa a igreja ao movimento pentecostal pois, segundo ela, os preceitos da Igreja estão fundados nos dons do Espírito Santo e na descida deste em Pentecostes, no falar línguas estranhas, nas curas divinas e nas profecias (Entrevistado I) ${ }^{2}$.

Para esta pesquisa, é importante reconhecer o território da IPBR, bem como a análise temporal de sua formação. Para o geógrafo Raffestin (1993, p. 127) "sendo uma organização, toda igreja se comporta da mesma maneira que qualquer outra organização: procura se expandir, reunir, controlar e gerenciar”.

Propóe-se uma análise espaço-temporal iniciada no ano de fundação da igreja, 2009, e que se estende até o ano de 2017. Como a Igreja não dispóe de documentos que indiquem sua espacialidade desde sua fundação, o levantamento está baseado na pesquisa de campo e questionários. Desse modo propóe-se três períodos: o primeiro se estende de 2009 a 2014, o segundo de 2014 a 2016 e o terceiro se estende de 2016 a 2017.

1 Para facilitar o entendimento do que será exposto adiante, destaca-se que a IPBR contava com apenas uma filial no momento da pesquisa, porém, em períodos anteriores, já havia feito tentativas de gerir e manter templos filiais (como o da Pedreira), mas sem sucesso, alguns sendo fechados logo após sua implementação.

2 Entrevista concedida por: Entrevistado I (Pastora presidente da IPBR). Entrevista I. (Ago. 2016). Entrevistador: Paulo Afonso Dias de Lima. Ananindeua, 2016. 
O primeiro período teve início com a fundação da Igreja. Segundo informações obtidas, a igreja iniciou o trabalho com um templo e, pouco depois, surgiram quatro células. A Igreja manteve essa organização espacial durante a maior parte desses cinco anos (Entrevistado I).

Em 2014, a Igreja passou por algumas mudanças, principalmente causadas pela chegada de uma quantidade grande de pastores e membros advindos de outras instituiçôes religiosas pentecostais. Ingressam na IPBR, nessa época, mais de 30 membros (Entrevistado I).

Quando perguntado o porquê da mudança de igreja, um dos membros que dela participou respondeu:

\begin{abstract}
Faltava apoio na outra Igreja, nós estávamos em uma filial e nós fomos totalmente esquecidos pela igreja mãe. Com a graça de Deus, nós ainda mantemos por muito tempo o templo, tirávamos do nosso bolso para pagar o aluguel, além, claro, da ajuda dos irmãos que estavam ali com a gente. A IPBR foi uma das igrejas que nos auxiliou espiritualmente e conhecíamos já o seu trabalho quando tomamos a decisão de sairmos de onde estávamos e partirmos para ajudar na obra de Deus com a IPBR (Entrevistado II $)^{3}$.
\end{abstract}

No segundo período, a Igreja experimenta um grande crescimento. Um dos fatores responsáveis é multiplicação das suas células, que passam de quatro para 17 , além da mudança de seu Templo principal para um prédio maior visando acomodar um maior número de pessoas. Ocorre nesse período a abertura de um templo filial no bairro da Pedreira em Belém (Entrevistado I).

No início do terceiro período, a Igreja busca consolidar seu crescimento, abrindo no bairro da Cabanagem, em Belém, seu segundo templo filial. Fica evidente o seu crescimento, porém, já no final de 2016, a IPBR começa a retroceder. O templo filial da Pedreira é fechado devido ao custo para mantê-lo e à distância em relação à sede. De 17 células, a igreja encontra-se atualmente com 12 (Entrevistado III) ${ }^{4}$.

Considera-se, portanto, que mesmo que essa característica fugaz da territorialidade pentecostal, mantida pela IPBR, tivesse dado condiçóes para a mesma expandir seu território rapidamente, ela não foi capaz de criar uma organização necessária para mantê-lo. A estrutura da igreja não estava preparada para o crescimento que ela se propôs a alcançar.

Sobre essa perspectiva, quando perguntado sobre os benefícios e dificuldades da estrutura e organização da Igreja, um dos pastores relatou que "antes de expandir e abrir novas células e novos templos, é necessário que a Igreja faça um planejamento. Não se pode abrir templos e células sem uma preparação. A Igreja precisa funcionar como uma empresa neste aspecto" (Entrevistado III). Identifica-se, através da da resposta do entrevistado, que houve precipitação e falta de organização para que a instituição religiosa se expandisse.

3 Entrevista concedida por: Entrevistado II (Membro). Entrevista II. (Jan. 2017). Entrevistador: Paulo Afonso Dias de Lima. Ananindeua, 2017.

4 Entrevista concedida por: Entrevistado III (Pastor da filial na Cabanagem). Entrevista III. (Jan. 2017). Entrevistador: Paulo Afonso Dias de Lima. Ananindeua, 2017. 
Pode-se concluir que o fato de a igreja ter uma estrutura mais descentralizada é desfavorável quando se considera a rapidez com que a mesma aumenta seu território e seu número de fiéis, porém apresenta fragilidade quanto à efemeridade deste crescimento.

A territorialidade informal e fugaz possui um aspecto dialético, segundo Machado (1994, p. 161), "marca, portanto, uma específica forma de apropriação espacial fundamentalmente dinâmica, transitória, efêmera e, mais ainda, hodierna, capaz de marchar, lado a lado, com a experiência ambiental da modernidade [...]." A partir da dinâmica das células, percebe-se que a IPBR as utiliza como principal ação/prática territorial, tanto para a manutenção quanto na aquisição de novos territórios.

As células funcionam como territorialidades, considerando-se importante ressaltar que, no aspecto religioso, estas estão baseadas complementarmente tanto nas práticas de controle do território quanto nas experiências simbólicas e ideológicas que o legitimam.

Em síntese, a territorialidade religiosa, na abordagem da geografia cultural, contempla duas açóes estratégicas complementares que legitimam a fé:

(i) As práticas desenvolvidas por religiosos que necessitam controlar o território religioso;

(ii) Todas as experiências religiosas coletivas ou individuais que o grupo mantém com o lugar (es) sagrado (s) e nos itinerários que constituem seu território (Filipe, 2013, p. 83).

A análise se manterá exclusivamente na dinâmica de células, visto que não é objetivo do trabalho relacionar aqui todas as dinâmicas do território religioso da IPBR, mas identificar a principal prática e suas características.

\section{As células da Igreja Profética Batista da Restauraçáo (IPBR) como estratégias de controle e ampliaçáo de territórios ${ }^{5}$}

As células, no âmbito religioso, podem ser definidas como pequenos grupos que reúnem-se nos lares dos membros, com a função de difundir a mensagem cristã de uma forma interpessoal e descentralizada. Uma tentativa de contemplar, principalmente, aqueles que não se sentem confortáveis em ir ao templo e consolidando novos convertidos por meio dos estudos bíblicos. Para elucidar o modelo de células em uma igreja, utiliza-se a fala de Comiskey (2008, p. 20):

As Células são grupos pequenos abertos focalizados no evangelismo que estão embutidos na vida da igreja. Elas se reúnem semanalmente para que os seus participantes se edifiquem uns aos outros como membros do corpo de Cristo e para anunciar o evangelho àqueles que não conhecem Jesus. O objetivo principal de cada célula é multiplicar-se à medida que o grupo cresce por meio do evangelismo e das conversóes que seguem. Dessa maneira, os novos membros são acrescentados à Igreja e ao Reino de Deus. Os membros das Células também são encorajados a participar do culto de celebração da igreja inteira, quando as células se encontram para adoraçáo (Comiskey, 2008, p. 20).

5 Várias análises são possíveis a partir do estudo sobre a dinâmica de células de determinada instituição. Nesta pesquisa, em virtude do objetivo proposto, as células serão estudadas por seu aspecto espacial/territorial, de suporte às açóes de poder da Igreja. 
A célula possui múltiplas funções. A função de alcançar as pessoas mais distantes da Igreja, consolidando-as por meio da criação de uma rede de difusão da mensagem evangélica. A Figura 1 representa o Processo de difusão cristã, conforme análise de Filipe (2013), e mostra a simulação da espacializaçáo do processo num grupo de relacionamento entre a pessoa crente e familiares/amigos não crentes: "(i) uma pessoa se converte; (ii) ocorre superação da resistência pela recepção repetida de informaçōes pelo convertido inicial; (iii) encontro semanal na célula garante o intervalo de tempo constante" (Silva, 1995, p. 29-30 apud Filipe, 2013, p. 100).

\section{Figura 1 - Processo de difusáo cristá, igreja em células}

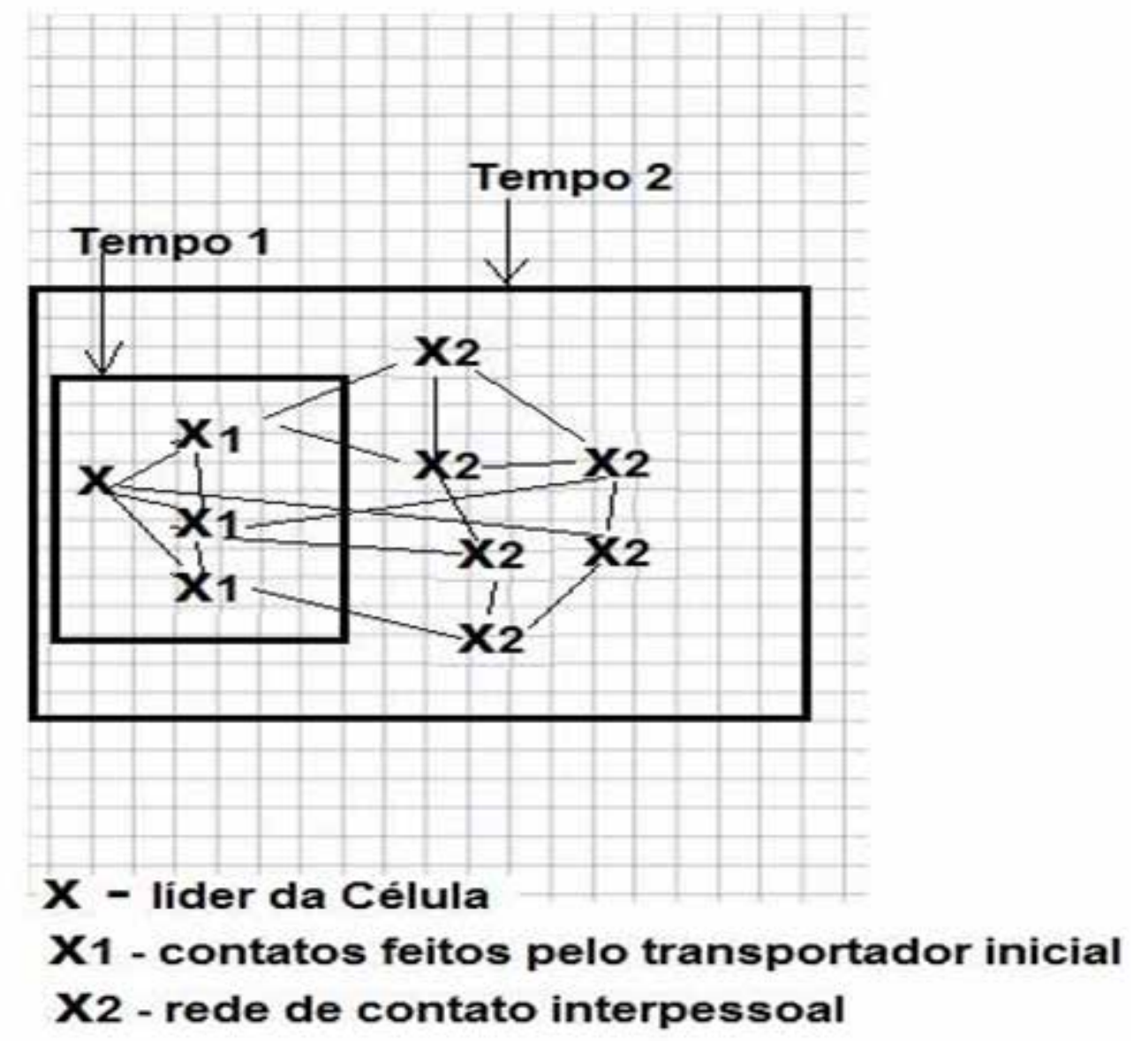

Fonte: Silva, 1995 apud Filipe, 2013, p. 101.

Observa-se que a célula é a dinâmica pela qual ocorre o fluxo de toda a informação cristã evangelística e que proporciona o aparecimento de uma rede, na qual os indivíduos sáo, ao mesmo tempo, receptores e transmissores das mensagens, doutrinas e comandos estabelecidos no centro de origem, a Igreja.

Após ter estabelecido o caminho que distribui o fluxo das mensagens religiosas, o resultado esperado é a aprendizagem que envolve a aceitação das ideias religiosas, a consecutiva expansão da área de abrangência com respectivo crescimento numérico de membros da religiáo em questão (Filipe, 2013, p. 100). 
Os líderes religiosos da IPBR identificaram a dinâmica de células como a prática mais eficiente na busca por fiéis, uma vez que ela proporciona inúmeras vantagens, se for bem estruturada e tratada de uma maneira "empresarial", como eles próprios consideram (Entrevistado IV) ${ }^{6}$. Relacionando-as com a análise de Filipe (2013), compreende-se que o processo de discipulado nas células da IPBR busca: "(a) os processos flexíveis de difusão/recepção das doutrinas; (b) gerenciamento e capacitação de líderes/ equipes (c) expansão/consolidação das células/redes/igrejas. (d) conexão com outras redes para suporte e difusáo da inovação" (Filipe, 2013, p. 105).

A primeira característica que se destaca é a flexibilidade da dinâmica de células. Identificou-se que, para abrir uma célula, basta haver um membro disposto a ceder seu lar para a Igreja e, a partir daí, a difusão é feita, principalmente a partir da sua família e sua rede de amigos, que propagarão a mensagem doutrinária da IPBR (Entrevistado V) ${ }^{7}$.

Estas são utilizadas como uma extensão da igreja, criando uma maior interação entre os fiéis. Nas palavras do pastor entrevistado, "as células servem para cuidar melhor das ovelhas (fiéis)". As células dependem apenas de um lar, podendo se encontrar em qualquer parte da cidade, desde que tenham fiéis dispostos a criá-la. Por ocorrerem nos lares, às células não criam grandes custos para igreja (Lima; Dias, 2016, p. 12).

A segunda característica, e uma das maiores preocupaçóes da Igreja, é a preparação dos líderes. Pode-se inferir que a Igreja mantém um cuidado maior na formação de líderes, pois eles são os reprodutores principais das doutrinas e ideologias para os fiéis, representando o poder da Igreja sobre aquele lugar. A IPBR cria escolas específicas de formação de líderes e torna obrigatória a sua participação para que, então, possam estar aptos a ingressar em (ou se responsabilizar por) uma célula (Entrevistado IV).

A terceira característica que se destaca na Igreja é referente à expansão e consolidação das células. Essa descentralizaçáo ocorre, basicamente, por dois motivos: o primeiro é porque, a partir dessa expansão, a Igreja se expande para abrir novas células e novos templos. O segundo motivo deve-se ao fato de que a IPBR experimentou uma fase de regressão, muito em função da estrutura insuficiente para se adequar ao crescimento. A partir das entrevistas, foram levantados alguns pontos que, observamos, foram cruciais para esse retrocesso em seu crescimento.

A Igreja, como identificado anteriormente, conseguiu uma expansão rápida, porém ela não foi acompanhada de uma estrutura que sustentasse esta expansão. Que fatores foram identificados para o retrocesso do crescimento das células? Por meio das várias respostas obtidas, tanto de pastores quanto de membros, pudemos estabelecer alguns fatores contribuintes:

a) - O pequeno acompanhamento do supervisor geral;

b) - A falta de planejamento para se abrir e multiplicar uma célula;

c) - A localização da célula;

d) - A falta de anfitrião (pessoa que cede seu lar);

e) - A falta de líderes preparados;

6 Entrevista concedida por: Entrevistado IV (Pastor responsável pela coordenação das células da Igreja). Entrevista IV. (Jan. 2017). Entrevistador: Paulo Afonso Dias de Lima. Ananindeua, 2017.

7 Entrevista concedida por: Entrevistado V (Membro). Entrevista V. (Jan. 2017). Entrevistador: Paulo Afonso Dias de Lima. Ananindeua, 2017. 
Outra característica da dinâmica de células, identificada por meio das entrevistas feitas, foi a de que, além de difundir a mensagem e doutrina cristã por meio de uma rede interpessoal e descentralizada, ela também é importante na estruturação de uma rede geográfica que dá suporte ao território da Igreja.

Haesbaert (2004, p. 149) define rede como o "espaço organizado a partir de relaçóes sociais que priorizam a mobilidade e a fluidez, por meio de linhas ou dutos e polos ou nós (conexôes), necessários à dinâmica dos fluxos (materiais ou imateriais) que a fundamenta”. Importante ressaltar que as redes não surgem do nada - há intencionalidades de diversos agentes (hegemônicos ou hegemonizados) que produzem e apropriam-se do espaço.

Nesse sentido, compreende-se que as redes "estão presentes em todas as estratégias que os atores desencadeiam para dominar as superfícies e os pontos por meio da gestáo e do controle de distâncias" (Raffestin, 1993, p. 200). Possuem localizaçóes geográficas ligadas entre si por meio de conexóes e fluxos.

A dinâmica de redes busca uma organização do espaço, pois, ao territorializar-se, o sujeito se apropria do espaço e o organiza conforme seus interesses na tentativa de se manter, expandi-lo e/ou re-existir (Raffestin, 1993). Entáo, as redes, principalmente na atualidade, têm um conceito próximo ao de território. Em síntese, "territorializar-se significa também, hoje, construir e/ou controlar fluxos/redes e criar referências simbólicas num espaço em movimento, no e pelo movimento" (Haesbaert, 2004, p. 280).

Identifica-se, portanto, como a IPBR, na tentativa de controlar e expandir seu território, cria pontos no espaço, com os quais estabelece e controla os fluxos que alimentam toda a rede. A dinâmica de células, do modo como tem sido adotada, é primordial para o territorializar-se da Igreja; cria-se, então, um território que tem a dinâmica de redes como suporte (Haesbaert, 2004).

A Figura 2 mostra o território-rede da IPBR como forma de elucidar as consideraçóes apontadas acima:

\section{Figura 2 - Território-rede da IPBR.}

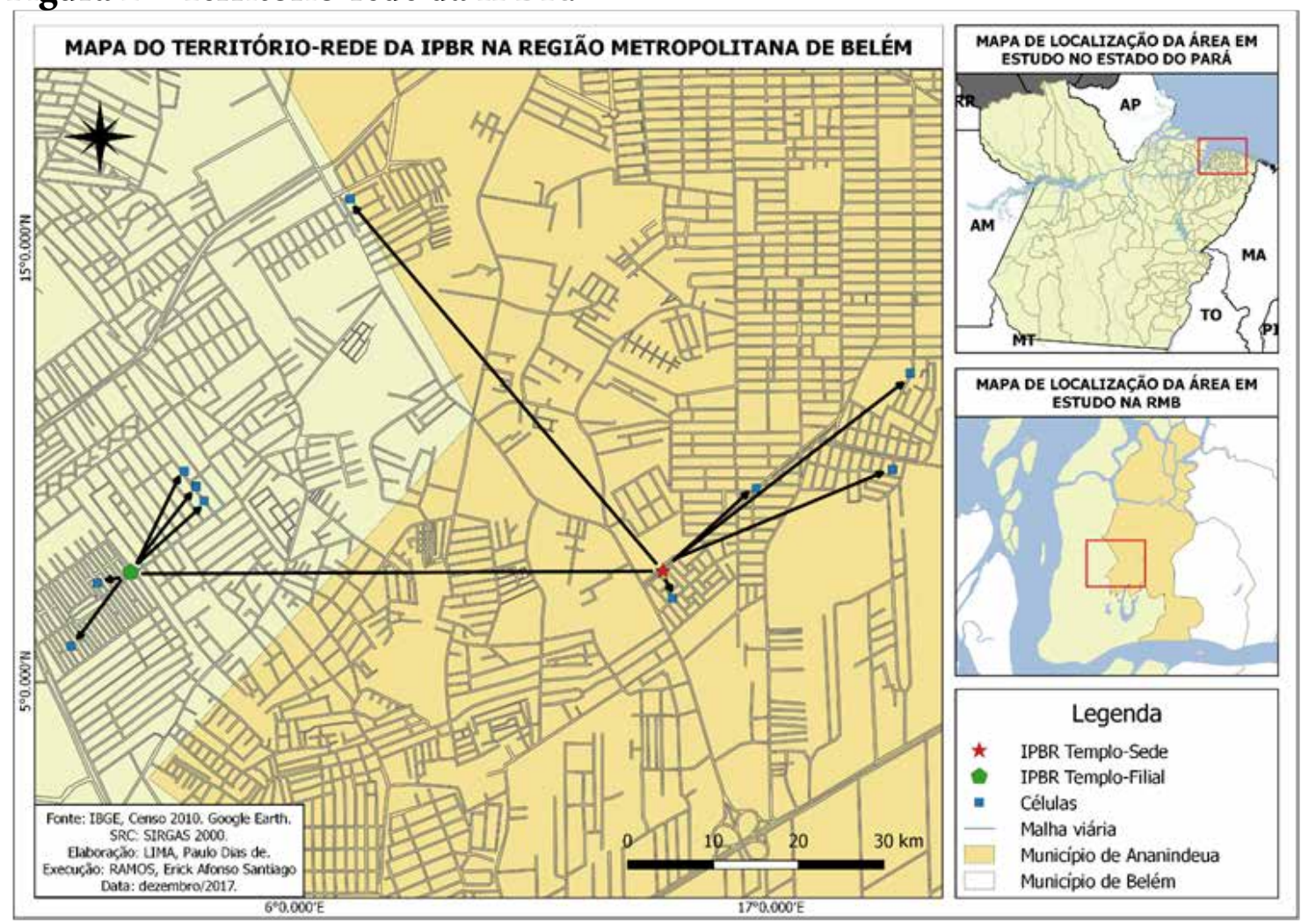

Fonte: Elaboração do autor, 2017. 
A partir da imagem, é possível identificar a rede dos fluxos da IPBR e as células e templos quanto à materialidade, dando suporte a estes fluxos. Considera-se que a célula é a estratégia de crescimento e manutenção do território mais eficaz de igrejas pentecostais como a IPBR, pois é uma forma de territorialidade mais dinâmica. Além disso, sua informalidade proporciona que a célula aconteça nos lares de fiéis ou pessoas que não são da religiáo, facilitando a difusão dessa crença no espaço.

\section{Consideraçóes finais}

Os estudos de Sack (1986), Rosendahl (2003, 2007, 2012), Haesbaert (2004, 2007) e Machado (1994) foram de grande relevância para se entender o território religioso e as territorialidades da IPBR. Através da análise empírica, identificou-se a dinâmica de células como a estratégia mais importante da Igreja para a manutenção, difusão de sua fé/prática e aquisiçáo de novos territórios. As características dessa dinâmica também foram conhecidas, sua flexibilidade na difusão/recepção das doutrinas, a importância dada à capacitação de líderes (responsáveis por serem os difusores iniciais da mensagem doutrinária da Igreja) e o processo de multiplicaçáo da Igreja e sua dupla característica.

As células são, assim, a prática adotada pela Igreja que mais corrobora sua expansão, porém destaca-se, também, que seu aspecto flexível a torna uma dinâmica difícil de ser administrada. Dessa forma, a expansão territorial que é alcançada rapidamente com aporte nessa prática torna-se de difícil controle, forçando, em muitos casos, um recuo do território da Igreja.

A presente pesquisa cumpre seus objetivos, todavia outras proposições são também importantes para pesquisas posteriores na relação entre Geografia e Religião, instigando a continuação deste caminho:

- A análise do carisma do líder religioso e relaçóes de poder.

- A análise das festas religiosas na construção de identidades e afirmação com o lugar.

- A relaçáo entre religiáo e política em um contexto brasileiro contemporâneo.

Vê-se então a presente pesquisa não como um ponto de chegada, mas como um aporte a estudos em Geografia da Religiáo que privilegiem a dimensão política na atuação de igrejas pentecostais, principalmente tendo como base um contexto urbano.

\section{Referências}

COMISKEY, J. Crescimento explosivo da Igreja em Células: Levando seu grupo a crescer e multiplicar. 3. ed. Curitiba: Ministério Igreja em Célula, 2008.

CRESWELL, J. W. Procedimentos qualitativos. In: Projeto de pesquisa: métodos qualitativos, quantitativos e mistos. 2. ed. Porto Alegre: Artmed, 2007, pp. 184-210.

CORREIA, M. C. A Observação Participante enquanto técnica de investigação. Pensar Enfermagem, 13(2), 1999, pp. 30-36. 
DEMOGRÁFICO, IBGE C. Características gerais da população, religião e pessoas com deficiência. Rio de Janeiro: Instituto Brasileiro de Geografia e Estatística, 2010.

FILIPE, R. J. M. Difusão espacial da religião: Igreja Metodista em São Francisco, NiteróiRJ, a prática religiosa em células. 2014. 129 p. Dissertação (Mestrado em Geografia) UERJ, Rio de Janeiro, 2014.

FREITAS, W.; JABBOUR, C. Utilizando estudo de caso(s) como estratégia de pesquisa qualitativa: boas práticas e sugestóes. Estudo \& Debate, Lajeado, v. 18, n. 2, pp. 07-22, 2011.

GAASKELL, G. Entrevistas individuais e grupais. In: BAUER, M. W.; GAASKELL, G. (Editores). Pesquisa qualitativa com texto: imagem e som: um manual prático. $7^{\mathrm{a}} \mathrm{ed}$. Petrópolis: Vozes, 2012, pp. 295 - 316.

GEERTZ, C. A interpretação das culturas. 13. reimpr. Rio de Janeiro: LTC, 2008.

HAESBAERT, R. O mito da desterritorialização: do "fim dos territórios" a multiterritorialidade. Rio de Janeiro: Bertrand Brasil. 2004.

HAESBAERT, R. Território e multiterritorialidade: um debate. Geografia, v. 17, 2007.

HASTRUP, K; HERVIK, P. Social Experience and Anthropological Knowledge. Routledge, London. 1994.

LIMA, P. A. D. de. DIAS, A. P. Territórios de instituições religiosas: uma análise das territorialidades da Igreja Evangélica 'Filhos da Promessa' e da paróquia 'São Pedro e São Paulo’ em Belém - PA. In: $2^{0}$ Simpósio Internacional de História das Religióes (Comunicação Oral), 2016.

MACHADO, M. S. A territorialidade pentecostal: um estudo de caso em Niterói. Revista Brasileira de Geografia, Rio de Janeiro, no 56 (1/4), pp. 135-164. Jan/dez 1994.

MÓNICO, L. et al. A Observação Participante enquanto metodologia de investigação qualitativa. In: Congreso Íbero-Americano en Investigación Cualitativa. 2017.

RAFFESTIN, C. Por uma geografia do poder. São Paulo: Ática, 1993.

ROSENDAHL, Z. Espaço, cultura e religião: dimensões de análise. In: CORREAA, R. L; ROSENDAHL, Z. (Orgs.). Introdução à geografia cultural. Rio de janeiro: Bertrand Brasil, 2003, pp. 187-221.

ROSENDAHL, Z. Território e territorialidade: uma perspectiva geográfica para o estudo da religião. In: anais do X encontro de geógrafos da américa latina - EGAL. 2005.

ROSENDAHL, Z. O sagrado e sua dimensão espacial. In: CASTRO, I. E. de; GOMES, P. C. da C.; CORREAA, R. L. (Orgs.). Olhares geográficos: modos de ver e viver o espaço. Rio de janeiro: Bertrand Brasil, 2012, pp. 73-99.

SACK, R. D. Territorialidade Humana: sua teoria e história. Cambridge: Cambridge University Press, 1986. 
SOUZA, M. L. de. O território: sobre espaço e poder, autonomia e desenvolvimento. In: CASTRO, I. E. de; CORREAA, R. L.; GOMES, P. C. da C. (Orgs.). Geografia: conceitos e temas. $2^{\mathrm{a}}$ ed. Rio de Janeiro; Bertrand Brasil, 2000, pp. 77-116.

SOUZA, M. L. de. Território e (des)territorialização. In: SOUZA, M. L. de. Os conceitos fundamentais da pesquisa sócio-espacial. 1. ed. Rio de Janeiro: Bertrand Brasil, 2013, pp. 77-110.

SOUZA, M. L. de. Redes. In: SOUZA, M. L. de. Os conceitos fundamentais da pesquisa sócio-espacial. 1 ed. Rio de Janeiro: Bertrand Brasil, 2013, pp. 163-178.

YIN. R. K. Estudo de caso: planejamento e métodos. 3. ed. Porto Alegre: Bookman, 2005.

Recebido: 29 de janeiro de 2019.

Aprovado: 17 de outubro de 2019. 